\title{
Crescimento e rendimento do algodoeiro BRS-200 com aplicações de cloreto de mepiquat e lâminas de irrigação
}

\author{
Francisco P. Cordão Sobrinho ${ }^{1}$, Pedro D. Fernandes ${ }^{1}$, Napoleão E. de M. Beltrão ${ }^{2}$, Frederico A. L. Soares ${ }^{1} \&$ Cícero P. C. Terceiro Neto ${ }^{1}$
}

\begin{abstract}
RESUMO
Visando contribuir para a melhoria do nível tecnológico da cotonicultura regional, conduziu-se um experimento na estação experimental da EMBRAPA Algodão, em Barbalha, CE, no período de agosto a novembro de 2003, com o objetivo de se estudar o crescimento e o rendimento do algodoeiro BRS 200 Marrom, submetido a quatro doses do regulador de crescimento cloreto de mepiquat $\left(0,50,75\right.$ e $100 \mathrm{~g}$ i.a. ha $\left.{ }^{-1}\right)$ e cinco lâminas de irrigação $(125,30,298,35,353,89,521,86$ e 741,64 mm); o delineamento estatístico foi em blocos ao acaso, com 4 repetições e arranjo fatorial 4 x 5. A aplicação de $741,64 \mathrm{~mm}$ resultou em aumento de $339 \%$ na produtividade do algodoeiro. Não se constatou efeito interativo entre lâminas de irrigação e doses de cloreto de mepiquat mas este, no nível de $100 \mathrm{~g}$ i.a. ha-1, reduziu as variáveis de crescimento sem, no entanto, afetar o rendimento nem a abertura do primeiro capulho do algodoeiro.
\end{abstract}

Palavras-chave: Gossypium hirsutum L., regulador de crescimento, produção de fibra

\section{Growth and yield of BRS 200 cotton with application of mepiquat chloride and irrigation levels}

\begin{abstract}
Aiming to contribute to the elevation of technological level in cotton cultivation, this work was carried out in EMBRAPA Cotton Experimental Station in Barbalha, Ceará State, Brazil, in the period of August to November, 2003, with the objective of studying the growth and yield of BRS 200 Brown cotton submitted to four doses of mepiquat chloride $(0,50,75$ and $100 \mathrm{~g}$ i.a. $\left.\mathrm{ha}^{-1}\right)$ and five irrigation levels $(125.30,298.35,353.89,521.86$ and $741.64 \mathrm{~mm})$, in randomized block design, with 4 replications. The irrigation with $741.64 \mathrm{~mm}$ resulted in a 339\% increase in cotton yield. There was no interactive effect between irrigation levels and mepiquat chloride factors, but the growth regulator, at $100 \mathrm{~g}^{\text {i.a. }} \mathrm{ha}^{-1}$, reduced the growth variables without affecting the yield or the first cotton boll opening.
\end{abstract}

Key words: Gossypium hirsutum L., growth regulator, fiber production

UAEAg/UFCG, Rua Aprígio Veloso 882, CEP 58109-970, Campina Grande, PB. Fone: (83) 3310-1185. E-mail: fcordao@cidadeinternet.com.br; pdantas@deag.ufcg.edu.br; fredantonio1@yahoo.com.br; cicerocordao@yahoo.com.br

2 Embrapa Algodão, Rua Osvaldo Cruz 1143, CEP 58107-720, Campina Grande, PB. Fone: (83) 3315-4300. E-mail: nbeltrão@cnpa.embrapa.br 


\section{INTRODUÇÃO}

O algodoeiro é uma espécie eminentemente de clima tropical, cultivada na maioria das regiões de clima quente e suas fibras são responsáveis pelo vestuário de mais de $45 \%$ da humanidade (Beltrão, 1999). O Brasil, que sempre se destacou como grande produtor/exportador, reduziu a área de plantio e de produção, entre os anos de 1991 a 1997, chegando a ser o $2^{\circ}$ maior importador de algodão do mundo, cerca de 300.000 toneladas anuais de pluma; tais mudanças se deveram à abertura do mercado ao produto importado, com baixas taxas de juros anuais e em função de adversidades climáticas, coincidindo com problemas fitossanitários (Barros \& Santos, 1997; CONAB, 2003). Recentemente, tem ocorrido recuperação da safra nacional com a área plantada, em 2004/2005, de 1.151,8 mil hectares, produção de 1.392,3 mil toneladas de pluma e uma produtividade média, em algodão em caroço, de $46.703 \mathrm{Mg} \mathrm{ha}^{-1}$; o País passou, então, a ser o $5^{\circ}$ maior produtor de algodão do mundo e o $4^{\circ}$ exportador mundial, com exportação de 435.000 t e importação de $90.000 \mathrm{t}$ ao ano (CONAB, 2005).

A partir de 1979, a Dra. Sally Fox selecionou, no Texas, USA, algodões de fibra marrom e iniciou um processo de melhoramento genético (ICAC Recorder, 1992), em busca por produtos ecologicamente corretos, que não poluíssem o ambiente e dispensassem a necessidade de coloração artificial. Nesta mesma época se iniciaram, em Estados do Nordeste brasileiro, coletas de plantas de algodoeiros asselvajados, nas tonalidades creme e marrom, em misturas com algodoeiros brancos cultivados das espécies Gossypium barbadense L. e Gossypium hirsutum L., raça Marie Galante Hutch, conhecidos como algodões arbóreos (Freire et al., 1999). Esses algodoeiros foram preservados em bancos de germoplasma da Embrapa Algodão e serviram de base para os melhoristas desenvolverem a cultivar BRS 200 Marrom, considerada a primeira cultivar de algodão de fibras geneticamente coloridas, obtidas de um bulk (conjunto de linhagens fenotipicamente semelhantes) e derivada do algodão mocó, de natureza genética complexa, envolvendo pelo menos três espécies de algodão na sua origem (EMBRAPA, 2001).

Procurando minimizar os efeitos nocivos das secas periódicas e da irregularidade das chuvas sobre o rendimento da cultura, agricultores começam a mostrar interesse pela exploração da cotonicultura em regime de irrigação. Uma das vantagens desse cultivo é o curto período de ocupação da área (110 a 150 dias), baixo consumo de água (cerca de 4500 a $6000 \mathrm{~m}^{3} \mathrm{ha}^{-1}$ ) e boa produtividade, variando em função do ciclo da cultivar e das condições edafoclimáticas da região produtora (Almeida et al., 1990; Beltrão, 1999).

Com o desenvolvimento da cotonicultura irrigada, surgiu a tecnologia de uso de reguladores de crescimento, substâncias sintéticas que interferem na biossíntese do hormônio vegetal giberelina (Reddy et al., 1995; Lamas, 2001), visando reduzir o crescimento das plantas e proporcionar maior equilíbrio entre as partes reprodutivas e vegetativas, melhorando a sua eficiência na distribuição de fotoassimilados (Meredith Junior \& Wels, 1989; Atahyde \& Lamas, 1999). Interferindo no metabolismo vegetal, os cotonicultores visam obter plantas mais compactas, mais uniformes e mais precoces, com menor incidência de pragas e maior eficiência na colheita. O produto mais utilizado vem sendo o cloreto de mepiquat (Guthrie et al., 1995), necessitando serem avaliados seus efeitos sobre crescimento, em diferentes intervalos de tempo.

Não havendo informações sobre uso de água e de reguladores de crescimento em algodoeiro BRS 200 Marrom, recentemente lançada no mercado, realizou-se este trabalho com o propósito de se avaliar os efeitos de lâminas de irrigação e de doses de cloreto de mepiquat, sobre o crescimento e rendimento da cultura.

\section{MATERIAL E MÉTODOS}

O experimento foi conduzido na Estação Experimental da Embrapa, no município de Barbalha, CE, ano de 2003, com as seguintes coordenadas geográficas: latitude $07^{\circ} 19^{\prime} \mathrm{S}$, longitude $39^{\circ} 18^{\prime} \mathrm{W}$ e altitude de $415,74 \mathrm{~m}$. De acordo com a classificação climática de Thornthwaite \& Mather (1955), o clima do local é do tipo $\mathrm{C}_{1} \mathrm{~S}_{2} \mathrm{~A}^{\prime}$ a', ou seja, clima seco subúmido, com excesso hídrico no inverno. Conforme dados da SUDENE (1979), a estação chuvosa no município de Barbalha está limitada aos meses de janeiro a julho, com precipitação pluviométrica média anual de 1001,4 mm e temperatura média mensal superior aos $23,5^{\circ} \mathrm{C}$, sendo os meses de outubro a dezembro os mais quentes do ano.

A partir de amostras de solo, retiradas aos 0-30 e 30-60 cm, realizaram-se análises físico-hídricas no Laboratório de Irrigação e Salinidade da Universidade Federal de Campina Grande, UFCG, e análises químicas em amostras coletadas na profundidade 0-30 cm no Laboratório de Solos da Embrapa Algodão, cujos dados estão expostos na Tabela 1.

A cultivar utilizada no experimento foi a BRS 200 Marrom, um bulk constituído pela mistura, em partes iguais, de 3 linhagens de algodão, selecionadas a partir de algodoeiros arbóreos

Tabela 1. Caracterização físico-hídrica (profundidades 0-30 e 30-60 cm) e química $(0-30 \mathrm{~cm})$ do solo da área experimental da Embrapa Algodão, localizada no município de Barbalha, CE, 2003

\begin{tabular}{llcc}
\hline \multirow{2}{*}{ Características } & Unidade & \multicolumn{2}{c}{ Profundidade do solo (cm) } \\
\cline { 2 - 4 } Areia & $\left(\mathrm{g} \mathrm{kg}^{-1}\right)$ & $\mathbf{0}-\mathbf{3 0}$ & $\mathbf{3 0 - 6 0}$ \\
Silte & $\left(\mathrm{g} \mathrm{kg}^{-1}\right)$ & 26,32 & 31,30 \\
Argila & $\left(\mathrm{g} \mathrm{kg}^{-1}\right)$ & 22,84 & 22,98 \\
Densidade real & $\left(\mathrm{g} \mathrm{kg}^{-1}\right)$ & 49,42 & 45,72 \\
Densidade global & $\left(\mathrm{g} \mathrm{kg}^{-1}\right)$ & 2,53 & 2,66 \\
Porosidade total & $(\%)$ & 1,30 & 1,29 \\
Água disponível & $(\%)$ & 48,62 & 47,64 \\
Capacidade de campo & $(\%)$ & 14,92 & 14,01 \\
Ponto de murcha & $(\%)$ & 29,21 & 27,59 \\
Classificação textural & - & 14,29 & 13,58 \\
Matéria orgânica & $\mathrm{g} \mathrm{kg}^{-1}$ & Argiloso & Argila \\
pH & - & 22,73 & \\
P & $\mathrm{mg} \mathrm{dm}^{-3}$ & 6,9 & \\
$\mathrm{~K}$ & $\mathrm{mmol}_{\mathrm{c}} \mathrm{dm}^{-3}$ & 11,27 & \\
Ca & $\mathrm{mmol}_{\mathrm{c}} \mathrm{dm}^{-3}$ & 10,1 & \\
Mg & $\mathrm{mmol}_{\mathrm{c}} \mathrm{dm}^{-3}$ & 50,0 & \\
$\mathrm{Na}$ & $\mathrm{mmol}_{\mathrm{C}} \mathrm{dm}^{-3}$ & 4,0 & \\
Al & $\mathrm{mmol}_{\mathrm{c}} \mathrm{dm}^{-3}$ & 0,0 & \\
\hline & & & \\
\hline
\end{tabular}


nativos do semi-árido nordestino, com produtividade 64\% superior à da cultivar de algodoeiro mocó CNPA 5M (EMBRAPA, 2000); é tolerante à seca, de ciclo perene, com três anos de exploração econômica, podendo ser cultivada em condições de sequeiro nas áreas zoneadas para exploração do algodoeiro arbóreo; pode ser explorada, também, sob condições irrigadas no semi-árido, possibilitando a obtenção de rendimentos de até $3.300 \mathrm{~kg}$ de algodão em caroço, por hectare (EMBRAPA, 2000).

Em razão dos resultados da análise do solo, não houve necessidade de adubação fosfatada, pois a quantidade de fósforo existente no solo supria a carência da planta (EMBRAPA, 2000); adubações nitrogenada e potássica foram realizadas em três épocas sendo aplicados, na primeira época, $10 \mathrm{~kg} \mathrm{ha}^{-1}$ de uréia e $20 \mathrm{~kg} \mathrm{ha}^{-1}$ de cloreto de potássio, em cobertura aos 15 dias após emergência; a segunda cobertura, no início do botoamento, e a última, no começo do florescimento, foram realizadas com $20 \mathrm{~kg} \mathrm{ha}^{-1}$ de uréia e $20 \mathrm{~kg} \mathrm{ha}^{-1}$ de cloreto de potássio.

Os tratamentos consistiram de quatro doses do regulador de crescimento cloreto de mepiquat $\left(D_{1}=0, D_{2}=50, D_{3}=75\right.$ e $\mathrm{D}_{4}=100 \mathrm{~g}$ i.a. ha $\mathrm{h}^{-1}$, correspondentes a $0,1,1,5$ e $2 \mathrm{~L} \mathrm{ha}^{-1}$ de Pix - nome comercial do produto), combinadas a cinco lâminas de irrigação $\left(\mathrm{L}_{1}=125,30, \mathrm{~L}_{2}=298,35, \mathrm{~L}_{3}=353,89\right.$, $\mathrm{L}_{4}=521,86$ e $\mathrm{L}_{5}=741,64 \mathrm{~mm}$ ), em esquema fatorial $4 \times 5$, no delineamento em blocos casualizados, com 4 repetições; a parcela foi constituída de 192 plantas, sendo 96 úteis. A irrigação foi por aspersão, consistindo de uma linha central de aspersores ('line source sprinkler irrigation'), na qual se introduz o fator dose de regulador de crescimento, no sentido da linha, enquanto as lâminas de irrigação são definidas por diferentes faixas de distribuição de água, à medida que se afasta da linha de aspersores do tipo rotativo (diâmetro do bocal de 5,6 x 3,2 mm, tubo de subida de 0,70 m e espaçamento de $12 \mathrm{~m}$ ), com coeficiente de uniformidade de distribuição de $85,8 \%$.

Realizou-se o controle de plantas invasoras com herbicida de pré-emergência (Glifosate, na dose de $5 \mathrm{~L} \mathrm{ha}^{-1}$ ) e um fixador (Will fix 1,5 $\mathrm{L} \mathrm{ha}^{-1}$ ), diluídos em $60 \mathrm{~L}$ de água, aplicados com pulverizador costal, além de uma capina à enxada, para controlar a tiririca (Cyperus rotundus L.). Adotouse o manejo integrado de pragas (MIP) da Embrapa Algodão, realizando-se amostragens a cada 5 dias, a partir da emergência das plântulas até a abertura dos primeiros capulhos (Almeida \& Silva, 1999).

A partir dos dados obtidos em dois evapotranspirômetros de drenagem, instalados dentro da área experimental, determinaram-se a lâmina de controle e a evapotranspiração máxima da cultura (ETm), através do balanço hídrico proposto por Reichardt (1985), assim descrito:

$$
\Delta \mathrm{A}_{\mathrm{L}}=\mathrm{P}+\mathrm{I}-\mathrm{ETm}-\mathrm{RO}-\mathrm{DP}+\mathrm{AC}
$$

sendo: $\Delta \mathrm{A}_{\mathrm{L}}$ a variação do armazenamento de água no volume de solo considerado $(\mathrm{mm})$; $\mathrm{P}$ a precipitação pluviométrica (mm); I a água aplicada na irrigação (mm); ETm a evapotranspiração da cultura (mm); RO o escoamento superficial (mm); DP a drenagem profunda (mm) e AC, a ascensão capilar (mm). Considerando-se não ter ocorrido escoamento superficial nem ascensão capilar, a equação ficou restrita a:

$$
\Delta \mathrm{A}_{\mathrm{L}}=\mathrm{P}+\mathrm{I}-\mathrm{ETm}-\mathrm{DP}
$$

A lâmina controle $\left(\mathrm{L}_{4}\right)$ de água correspondeu a 100\% da evapotranspiração da cultura, calculada em função do evapotranspirômetro, localizando-se na segunda parcela a partir da linha de aspersores; a primeira parcela, a partir da linha dos aspersores, recebeu a lâmina maior $\left(\mathrm{L}_{5}\right)$, superior à do controle $\left(\mathrm{L}_{4}\right)$, e as três últimas, em função de sua localização receberam, sucessivamente, lâminas de água $\left(\mathrm{L}_{3}, \mathrm{~L}_{2} \mathrm{e}\right.$ $\mathrm{L}_{1}$ ) menores que a lâmina $\mathrm{L}_{4}$.

Após o semeio, as irrigações foram realizadas das 18:00 às 23:00 h e das 4:00 às 8:00 h, para se evitar os fortes ventos na região e aumentar a sua eficiência. As reposições de água para a cultura eram feitas quando havia depleção de 50\% da água disponível no solo, determinada através dos evapotranspirômetros de drenagem resultando, em média, em um turno de rega de sete dias.

Seguindo-se recomendações de Beltrão et al. (2001b), avaliou-se o crescimento, a intervalo de vinte dias, a partir da emergência das plântulas, através da amostragem de cinco plantas por parcela, obtendo-se dados das seguintes variáveis: altura de planta (comprimento do coleto à gema terminal), diâmetro caulinar (a $1 \mathrm{~cm}$ da superfície do solo) e área foliar a partir da equação proposta por Grimes \& Carter (1969):

$$
\mathrm{Y}=0,4322 \mathrm{x}^{2,3002}
$$

em que: Y é a área foliar e x é o comprimento da nervura principal de cada folha do algodoeiro.

A partir das plantas coletadas em cada amostragem, obtiveram-se os dados de fitomassa fresca (FF) e seca (FS) de raiz, caule e folhas, após secagem dos respectivos materiais, acondicionados em sacos de papel, a $65^{\circ} \mathrm{C}$, até peso constante.

Os dados foram submetidos à análise de variância e teste "F", com desdobramento dos graus de liberdade dos tratamentos em componentes de regressão, por serem fatores quantitativos (Ferreira, 2000).

\section{RESULTADOS E DISCUSSÃO}

Pela análise de variância dos dados das variáveis primárias de crescimento do algodoeiro (Tabela 2), ocorreu efeito significativo $(\mathrm{p}<0,01)$ do fator lâminas de irrigação, em todas as épocas de amostragem, exceto aos 40 dias após emergência (DAE) para fitomassa seca total (FST) e, aos 60 DAE, para a fitomassa fresca total (FFT). Com relação ao regulador de crescimento, a partir de 60 DAE não se constatou nenhum efeito significativo para as variáveis avaliadas; tampouco foi registrado efeito da interação entre os fatores (D x L), indicando que o efeito das lâminas de irrigação independe da aplicação do cloreto de mepiquat.

\section{Regulador de crescimento}

Embora não se tenha constatado efeito significativo dos tratamentos envolvendo doses do regulador de crescimento sobre o diâmetro caulinar (DC) verifica-se, pelas equações contidas na Tabela 3 , que aos $40 \mathrm{DAE}$, em relação aos 20 DAE, houve acréscimos em DC de 40,94, 102,16, 44,89 
Tabela 2. Resumo das análises de variância das variáveis primárias de crescimento do algodoeiro colorido BRS 200, com diferentes doses de cloreto de mepiquat e lâminas de irrigação

\begin{tabular}{|c|c|c|c|c|c|c|}
\hline \multirow{2}{*}{ Causas de variância } & \multicolumn{6}{|c|}{ Quadrados médios } \\
\hline & 20 DAE & 40 DAE & 60 DAE & 80 DAE & 100 DAE & 120 DAE \\
\hline \multicolumn{7}{|c|}{ Diâmetro caulinar } \\
\hline Regulador (D) & $0,62^{*}$ & $1,75 \mathrm{~ns}$ & $1,42^{\text {ns }}$ & $0,38^{\text {ns }}$ & $1,89^{\text {ns }}$ & $0,19^{\text {ns }}$ \\
\hline Lâmina (L) & $1,99 * *$ & $5,87 * \star$ & $18,85^{\star \star}$ & 55,92 ** & 55,30 ** & 30,96 ** \\
\hline$D \times L$ & $0,17^{\mathrm{ns}}$ & $0,56 n s$ & $0,86^{\mathrm{ns}}$ & $2,05^{\mathrm{ns}}$ & $2,03^{\mathrm{ns}}$ & $1,97^{\mathrm{ns}}$ \\
\hline Resíduo & 0,19 & 0,78 & 1,25 & 1,56 & 1,32 & 1,86 \\
\hline \multicolumn{7}{|c|}{ Altura de planta } \\
\hline Regulador (D) & $9,68 \mathrm{~ns}$ & $69,81 \mathrm{~ns}$ & $88,92^{\text {ns }}$ & $132,52^{\mathrm{ns}}$ & $266,60^{\mathrm{ns}}$ & $278,64^{\mathrm{ns}}$ \\
\hline Lâmina (L) & $65,08 * *$ & 301,99 ** & $1.354,28$ ** & $5.269,92$ ** & $5.341,07$ ** & $3.523,10$ ** \\
\hline$D \times L$ & $5,76^{\mathrm{ns}}$ & $29,74^{\mathrm{ns}}$ & $39,27^{\mathrm{ns}}$ & $94,86^{\mathrm{ns}}$ & $141,16^{\mathrm{ns}}$ & $208,33^{\text {ns }}$ \\
\hline Resíduo & 12,42 & 31,00 & 57,91 & 135,80 & 169,17 & 171,45 \\
\hline \multicolumn{7}{|c|}{ Área foliar } \\
\hline Regulador (D) & $37.588,83^{\star *}$ & $260.087,97$ ** & $634.418,61^{\mathrm{ns}}$ & $741.596,79^{n s}$ & $866.881,57^{\mathrm{ns}}$ & $741.596,79^{\mathrm{ns}}$ \\
\hline Lâmina (L) & $22.704,14^{\star *}$ & $326.025,60 * *$ & $4.681 .642,85^{* *}$ & $6.001 .676,02 * *$ & $7.693 .904,93 * *$ & $52.478 .986,83^{* *}$ \\
\hline$D \times L$ & $16.589,01^{\mathrm{ns}}$ & $32.951,92^{\mathrm{ns}}$ & $65.454,72^{\mathrm{ns}}$ & $122.851,81^{\mathrm{ns}}$ & $230.580,27^{\mathrm{ns}}$ & $15.763,84^{\mathrm{ns}}$ \\
\hline Resíduo & $3.623,76$ & $47.329,65$ & $50.953,41$ & $341.254,09$ & $2.285 .506,60$ & $2.110 .518,44$ \\
\hline \multicolumn{7}{|c|}{ Fitomassa fresca total } \\
\hline Regulador (D) & $10,08^{n s}$ & $12,70^{\mathrm{ns}}$ & $261,55^{\mathrm{ns}}$ & $421,45^{\text {ns }}$ & $1.472,02^{\mathrm{ns}}$ & $843,24^{\mathrm{ns}}$ \\
\hline Lâmina (L) & $21,41 * *$ & $225,75^{\star *}$ & $1.325,84^{\mathrm{ns}}$ & $4.546,23^{* *}$ & $4.602,12^{\star \star}$ & $2.806,10$ ** \\
\hline$D \times L$ & $9,93^{\text {ns }}$ & $54,63^{\mathrm{ns}}$ & $421,66^{\mathrm{ns}}$ & $1.011,83^{\mathrm{ns}}$ & $1.263,71^{\mathrm{ns}}$ & $1.545,69^{\mathrm{ns}}$ \\
\hline Resíduo & 5,67 & 46,37 & 145,24 & 757,51 & 908,85 & 770,88 \\
\hline \multicolumn{7}{|c|}{ Fitomassa seca total } \\
\hline Regulador (D) & $7,19 * *$ & $1,65^{\mathrm{ns}}$ & $81,2^{\text {ns }}$ & $130,84^{\mathrm{ns}}$ & $456,99^{n s}$ & $261,78^{\text {ns }}$ \\
\hline Lâmina (L) & $4,39 *$ & $14,63^{\text {ns }}$ & $610,51 * \star$ & $2.093,40 * \star$ & $2.119,14^{* *}$ & $1.292,12^{\star *}$ \\
\hline$D \times L$ & $4,11^{\star \star}$ & $7,17^{\mathrm{ns}}$ & $131,88^{\mathrm{ns}}$ & $316,47^{\mathrm{ns}}$ & $395,24^{\mathrm{ns}}$ & $483,44^{\mathrm{ns}}$ \\
\hline Resíduo & 1,38 & 6,23 & 145,24 & 236,92 & 284,25 & 241,11 \\
\hline
\end{tabular}

* $e^{* \star}$ Significativo a 0,05 e a 0,01 de probabilidade, respectivamente; ns - não significativo

e 41,19\%, respectivamente, correspondentes às doses de 0 , 50, 75 e 100 g i.a. ha-1 de cloreto de mepiquat; aos 60 DAE, esses acréscimos foram de 53, 103, 59 e 56\% em relação aos $40 \mathrm{DAE}$, enquanto aos $80 \mathrm{DAE}$, em relação aos $60 \mathrm{DAE}$, foram de 44, 103, 53 e 53\%, para as mesmas doses; aos 100 DAE, a dose de 100 g i.a. ha ${ }^{-1}$ não promoveu acréscimo em relação aos $80 \mathrm{DAE}$, sendo que nas doses de 0 , 50 e 75 g i.a. ha-1 de cloreto de mepiquat, os acréscimos foram de 15,100 e $14 \%$, respectivamente. Por esses dados, nota-se que os maiores acréscimos foram obtidos na dose de $50 \mathrm{~g}$ i.a. ha ${ }^{-1}$ como, também, o maior índice de crescimento do diâmetro caulinar foi no período de 40 a 60 DAE.

Tabela 3. Modelos matemáticos das variáveis de crescimento do algodoeiro colorido BRS 200, em função das doses do cloreto de mepiquat

\begin{tabular}{|c|c|c|}
\hline Causa de variação & Equação & $\mathbf{R}^{2}$ \\
\hline \multicolumn{3}{|l|}{ Diâmetro caulinar } \\
\hline $\mathrm{D}_{1}=0 \mathrm{~g}$ i.a. ha ${ }^{-1}$ & $Y=2,635^{\star}+0,000615^{\star} x^{2} \ln x-0,000020999^{\star} x^{3}$ & 0,90 \\
\hline $\mathrm{D}_{2}=50 \quad "$ & $Y=3,1394^{*}+0,0005409^{\star} x^{2} \ln x-0,00001885^{\star} x^{3}$ & 0,93 \\
\hline $\mathrm{D}_{3}=75 \quad "$ & $Y=2,985^{\star}+0,000559^{\star} x^{2} \ln x-0,00001887^{\star} x^{3}$ & 0,96 \\
\hline $\mathrm{D}_{4}=100$ & $Y=3,0762^{*}+0,000506^{*} x^{2} \ln x-0,00001637^{\star} x^{3}$ & 0,97 \\
\hline \multicolumn{3}{|l|}{ Altura de planta } \\
\hline$D_{1}=0$ g i.a. ha ${ }^{-1}$ & $Y=12,9148^{*}+0,00371^{*} x^{2} \operatorname{In} x-0,0001124^{\star} x^{3}$ & 0,98 \\
\hline $\mathrm{D}_{2}=50 \quad "$ & $Y=16,8291^{*}+0,00288^{\star} x^{2} \operatorname{In} x-0,00009166^{*} x^{3}$ & 0,98 \\
\hline $\mathrm{D}_{3}=75 \quad "$ & $Y=16,2764^{*}+0,00276^{*} x^{2} \ln x-0,00008614^{\star} x^{3}$ & 0,99 \\
\hline $\mathrm{D}_{4}=100$ & $Y=18,3397^{\star}+0,00268^{\star} x^{2} \ln x-0,000082^{\star} x^{3}$ & 0,97 \\
\hline \multicolumn{3}{|l|}{ Área foliar por planta } \\
\hline$D_{1}=0$ g i.a. ha ${ }^{-1}$ & $Y=126,7856^{\star}+2675,7088^{\star} /\left(1+\exp \left(-\left(x-63,5423^{\star}\right) / 9,6064^{\star}\right)\right)$ & 0,99 \\
\hline$D_{2}=50 \quad "$ & $Y=272,926^{\star}+1830,6097^{\star} /\left(1+\exp \left(-\left(x-63,39^{\star}\right) / 6,706^{\star}\right)\right)$ & 0,92 \\
\hline $\mathrm{D}_{3}=75 \quad "$ & $Y=-0,6972^{\star}+2994,004^{\star} /\left(1+\exp \left(-\left(x-64,916^{*}\right) / 14,185^{\star}\right)\right)$ & 0,99 \\
\hline $\mathrm{D}_{4}=100$ & $Y=139,2452^{\star}+2068,7795^{\star} /\left(1+\exp \left(-\left(x-54,8322^{*}\right) / 8,569^{\star}\right)\right)$ & 0,84 \\
\hline \multicolumn{3}{|l|}{ Fitomassa fresca total } \\
\hline $\mathrm{D}_{1}=0 \mathrm{~g}$ i.a. $\mathrm{ha}^{-1}$ & $Y=4250,99^{*} \operatorname{EXP}(-(X-96,02) / 11,84) /\left(1+\operatorname{EXP}\left(-\left(X-96,02^{*}\right) / 11,84^{*}\right)\right)^{2}$ & 0,92 \\
\hline $\mathrm{D}_{2}=50 \quad "$ & $Y=4273,89^{*} \operatorname{EXP}(-(X-95,71) / 10,78) /\left(1+\operatorname{EXP}\left(-\left(X-95,71^{*}\right) / 10,78^{*}\right)\right)^{2}$ & 0,89 \\
\hline $\mathrm{D}_{3}=75 \quad "$ & $Y=4248,35^{*} \operatorname{EXP}(-(x-95,63) / 11,92) /\left(1+\operatorname{EXP}\left(-\left(x-95,63^{*}\right) / 11,92^{*}\right)\right)^{2}$ & 0,99 \\
\hline $\mathrm{D}_{4}=100$ & $Y=4235,44^{*} \operatorname{EXP}\left(-(X-93,39) / 13,89^{*}\right) /\left(1+\operatorname{EXP}\left(-\left(X-93,39^{*}\right) / 13,89^{\star}\right)\right)^{2}$ & 0,98 \\
\hline \multicolumn{3}{|l|}{ Fitomassa seca total } \\
\hline $\mathrm{D}_{1}=0 \mathrm{~g}$ i.a. $\mathrm{ha}^{-1}$ & $Y=497,50^{*} \operatorname{EXP}(-(x-97,17) / 12,06) /\left(1+\operatorname{EXP}\left(-\left(x-97,17^{*}\right) / 12,06^{*}\right)\right)^{2}$ & 0,98 \\
\hline $\mathrm{D}_{2}=50 \quad "$ & $Y=4105,98^{*} \operatorname{EXP}(-(X-97,03) / 11,09) /\left(1+\operatorname{EXP}\left(-\left(X-97,03^{*}\right) / 11,09^{*}\right)\right)^{2}$ & 0,97 \\
\hline $\mathrm{D}_{3}=75 \quad "$ & $Y=498,85^{*} \operatorname{EXP}(-(x-97,33) / 11,09) /\left(1+\operatorname{EXP}\left(-\left(x-97,03^{*}\right) / 11,09^{*}\right)\right)^{2}$ & 0,98 \\
\hline $\mathrm{D}_{4}=100 \quad "$ & $Y=46,743^{*}-3,963^{*} x-0,094^{*} x^{2}-0,000517^{*} x^{3}$ & 0,87 \\
\hline
\end{tabular}




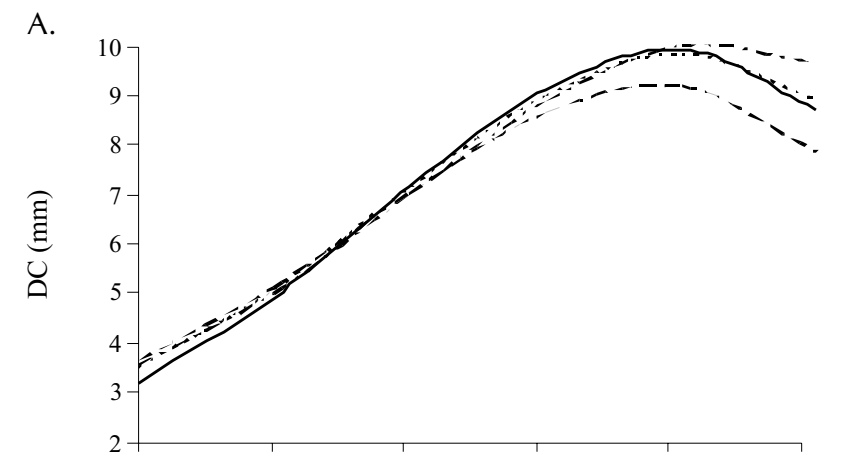

B.
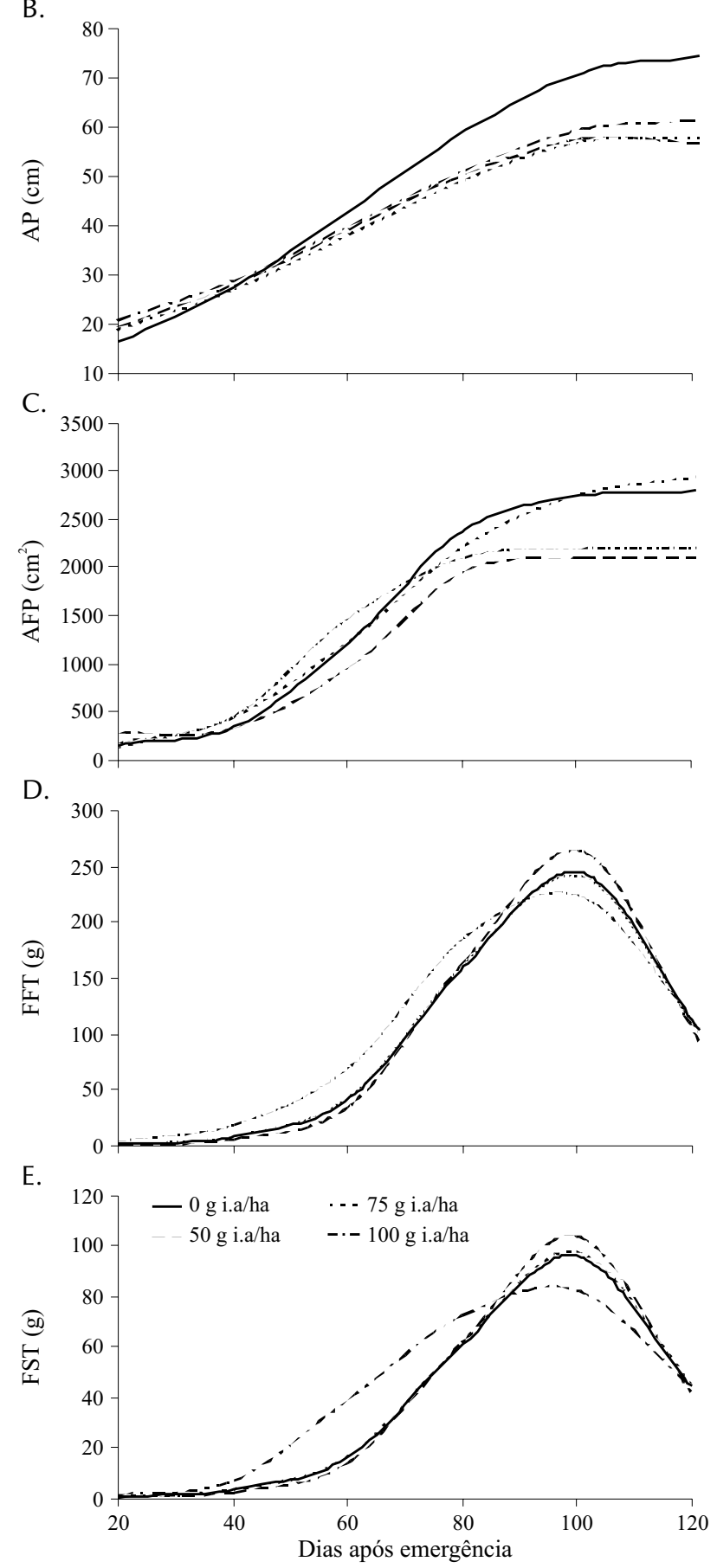

Figura 1. Efeitos das doses de cloreto de mepiquat sobre variáveis de crescimento (DC - diâmetro caulinar; AP - altura da planta; AFP - área foliar por planta; FFT - fitomassa fresca total; FST - fitomassa seca total) ao longo do ciclo (DAE) da cv. BRS 200 Marrom
O diâmetro caulinar (DC), embora sem ser afetado pelo regulador de crescimento, cresceu no período de 20 aos 100 DAE diminuindo, posteriormente, até os 120 dias, por ocasião das últimas coletas de plantas, decorrente, possivelmente, da mobilização de reservas para a formação final da produção, em que raízes e caules passaram a ser fonte para os frutos drenos (Figura 1A).

Quando se analisa o efeito do regulador de crescimento sobre a altura de plantas (AP) (Figura 1B) observa-se, pelas equações (Tabela 3), que a maior eficiência foi obtida com a dose de 50 g i.a. ha ${ }^{-1}$ do cloreto de mepiquat, com incremento de $192 \%$ em todo o ciclo, sendo 84 , 31 e 12\% inferior às doses de 0 , 75 e $100 \mathrm{~g}$ i.a ha-1, respectivamente; o crescimento foi crescente até os 90-100 dias após a emergência das plântulas, permanecendo constante após esta data (Figura 1B). Dados semelhantes foram observados por Beltrão et al. (2001b), em um experimento conduzido em campo de algodoeiro herbáceo, cultivar Delta Opal, irrigado com pivô central, utilizando o mesmo regulador de crescimento.

O aumento excessivo da área foliar pode prejudicar o seu desenvolvimento e a produção, passando a atuar como o principal dreno da planta (Taiz \& Zeiger, 2004); observa-se que a menor área foliar por planta (AFP) foi desenvolvida nas que foram pulverizadas com cloreto de mepiquat, na dose de $50 \mathrm{~g}$ i.a ha ${ }^{-1}$, aumentando cerca de $662 \%$ entre 20 e 120 DAE, contra 1700, 1798 e 700\% para as doses 0, 75 e 100 g i.a ha-1, respectivamente, no mesmo período (Figura 1C); a partir de 120 DAE começou a ocorrer abscisão de folhas.

Foi crescente o acúmulo de fitomassa fresca total (FFT) (Figura 1D) e de fitomassa seca total (FST) (Figura 1E) até os 100 dias de emergência das plântulas, observando-se nessa data, os menores valores com a dose de $100 \mathrm{~g}$ i.a. ha ${ }^{-1}$ do cloreto de mepiquat, caindo, drasticamente no final do ciclo, em todos os níveis do regulador de crescimento; analisando-se os dados das Figuras 1C, 1D e 1E, constata-se que, apesar de decréscimos de fitomassa após 100 DAE, a área foliar não decresceu, explicando-se o fato pela não contabilização da produção de fibras, resultando na diminuição da fitomassa total da planta. Na fase reprodutiva o dreno principal passou a ser os frutos, fato reportado na literatura (Chen et al., 2002), mobilizando as plantas as suas reservas para esses novos órgãos em formação.

\section{Lâminas de irrigação}

Todas as variáveis de crescimento da 'BRS Marrom' foram significativamente afetadas aos 120 dias de condução do experimento. A lâmina de 741,64 mm (Figura 2A) foi a que resultou em maior incremento no diâmetro caulinar, aos 100 DAE (197\%), quando comparado com os resultados observados aos 20 DAE; verifica-se também, através das equações, que o menor diâmetro caulinar foi registrado com a lâmina de irrigação de 125,30 mm.

O diâmetro das plantas decresceu à medida que diminuíram as lâminas de irrigação (Figura 2A), como decorrência natural das condições hídricas desfavoráveis para divisão e alongamento celular, afetando, sobretudo o câmbio caulinar (Raven et al., 2001; Taiz \& Zeiger, 2004). O crescimento do caule das plantas em diâmetro, ocorreu até os 100 dias após a emergência, decrescendo a partir daí; o maior diâmetro 
(7,9 mm) foi obtido com a lâmina de 741,64 mm $\left(\mathrm{L}_{5}\right)$, decrescendo para $10,9 \mathrm{~mm}$ quando as plantas foram irrigadas com 521,86 mm, valores superiores aos 9,86, 9,23 e 6,79 mm, registrados com as lâminas de 353,89, 298,35 e 125,30 mm, respectivamente.

O incremento do diâmetro do caule, constatado em função das lâminas de irrigação, veio confirmar fatos semelhantes relatados por outros autores (Souza, 1999; Souza et al., 1999), os quais detectaram diferenças significativas para os valores de diâmetro do caule obtidos em plantas irrigadas, em comparação com outras sem irrigação.

Concernente à altura de planta (Figura 2B) e com base nas equações contidas na Tabela 4 , com a lâmina de $741,64 \mathrm{~mm}$ as plantas cresceram mais, até os $100 \mathrm{DAE}$; com os três níveis mais altos de irrigação, a altura foi muito semelhante, sendo notória a grande diferença do crescimento das plantas, entre as três lâminas maiores e as duas menores. De acordo com as equações de regressão, as alturas máximas foram 75,35, 74,75, 72,05, 48,45 e 32,81 cm para as lâminas $\mathrm{L}_{5}, \mathrm{~L}_{4}, \mathrm{~L}_{3}, \mathrm{~L}_{2}$ e $\mathrm{L}_{1}$, respectivamente.

Constata-se que a maior exigência hídrica da cv. BRS 200 Marrom, em termos de altura de plantas, ocorreu no período compreendido entre a emissão dos primeiros botões florais (40 DAE) e o início de colheita (aproximadamente aos 100 DAE). A diferença de altura entre as plantas irrigadas com a maior lâmina e com as lâminas menores, é decorrente de insuficiência hídrica que provoca decréscimo na turgescência celular, diminuindo o crescimento por alongamento (Taiz \& Zeiger, 2004).
Quanto à área foliar, vê-se que os menores valores foram registrados nas plantas que receberam a menor lâmina de irrigação $\left(\mathrm{L}_{1}=125,30 \mathrm{~mm}\right)$, influindo, provavelmente, em número e tamanho de folhas e no somatório da área; nas plantas irrigadas com as maiores lâminas, a área foliar aumentou de forma senoidal, a partir dos $40 \mathrm{DAE}$ até os $80 \mathrm{DAE}$, estabilizando-se depois; entretanto, nas plantas estressadas esta relação só foi verificada a partir dos $50 \mathrm{DAE}$, começando a decrescer aos 70 DAE, ou seja, início da formação dos capulhos, indicando aceleração na senescência das folhas, em virtude da rápida mobilização de assimilados para os frutos, drenos economicamente importantes (Figura 2C). Ressalta-se ainda, que, na última avaliação realizada (120 DAE), a abscisão de folhas e a conseqüente redução da área foliar foram maiores nas plantas irrigadas com a menor lâmina.

Segundo Taiz \& Zeiger (2004), o primeiro efeito direto do déficit hídrico nas plantas é a redução da área foliar, por ser afetado o alongamento das células, fazendo com que seja formada a parede celular secundária, caracterizando o seu tamanho definitivo (Raven et al., 2001); no algodoeiro, ao ser afetada a divisão celular pelo agravamento do estresse hídrico, além de decréscimo na área foliar, diminui, também, o número de folhas emitidas (Silva et al., 1998).

Até os 50 DAE não houve efeito significativo das lâminas de irrigação sobre a fitomassa fresca e seca total, mas, após 60 DAE, o crescimento foi diferenciado e influenciado pelas lâminas de irrigação (Figuras 2D e E); nos tratamentos $\mathrm{L}_{3}(353,89 \mathrm{~mm})$ e $\mathrm{L}_{4}(521,86 \mathrm{~mm})$, praticamente não houve diferenças na fitomassa fresca e seca total (Figura 2D

Tabela 4. Modelos matemáticos das variáveis de crescimento do algodoeiro colorido BRS 200, em função das lâminas de irrigação

\begin{tabular}{|c|c|c|}
\hline Causas de variação & Equação & $\mathbf{R 2}$ \\
\hline \multicolumn{3}{|l|}{ Diâmetro caulinar } \\
\hline $\mathrm{L}_{1}=125,30 \mathrm{~mm}$ & $Y=3,1842^{\star}+0,0002926^{\star} x^{2} \ln x-0,000009866^{\star} x^{3}$ & 0,78 \\
\hline $\mathrm{L}_{2}=298,35$ & $Y=2,3012^{\star}+0,0004708^{*} x^{2} \ln x-0,00001475^{\star} x^{3}$ & 0,94 \\
\hline $\mathrm{L}_{3}=353,89$ & $Y=2,6261^{*}+0,0006379^{*} x^{2} \ln x-0,00002152^{\star} x^{3}$ & 0,99 \\
\hline $\mathrm{L}_{4}=521,86$ & $Y=3,2488^{\star}+0,0006525^{\star} x^{2} \ln x-0,00002237^{\star} x^{3}$ & 0,89 \\
\hline $\mathrm{L}_{5}=741,64$ & $Y=3,1169^{\star}+0,0007136^{\star} x^{2} \ln x-0,00002476^{\star} x^{3}$ & 0,98 \\
\hline \multicolumn{3}{|l|}{ Altura de planta } \\
\hline $\mathrm{L}_{1}=125,30 \mathrm{~mm}$ & $Y=19,404^{*}+0,000804^{\star} x^{2} \ln x-0,0000212^{\star} x^{3}$ & 0,70 \\
\hline $\mathrm{L}_{2}=298,35$ & $Y=14,513^{*}+0,00214^{*} x^{2} \ln x-0,0000646^{*} x^{3}$ & 0,97 \\
\hline $\mathrm{L}_{3}=353,89$ & $Y=12,7713^{\star}+0,00385^{\star} x^{2} \operatorname{In} x-0,000118^{\star} x^{3}$ & 0,97 \\
\hline $\mathrm{L}_{4}=521,86$ & $Y=15,1725^{\star}+0,00416^{*} x^{2} \ln x-0,0000132^{*} x^{3}$ & 0,98 \\
\hline $\mathrm{L}_{5}=741,64$ & $Y=17,5865^{\star}+0,00449^{*} x^{2} \ln x-0,000149^{*} x^{3}$ & 0,97 \\
\hline \multicolumn{3}{|l|}{ Área foliar por planta } \\
\hline $\mathrm{L}_{1}=125,30 \mathrm{~mm}$ & $Y=63,7704^{\star}+479,3797^{\star} /\left(1+\exp \left(-\left(x-35,9517^{*}\right) / 6,1485^{\star}\right)\right)$ & 0,99 \\
\hline $\mathrm{L}_{2}=298,35$ & $Y=86,3657^{*}+1418,9722^{\star} /\left(1+\exp \left(-\left(x-61,9205^{\star}\right) / 11,4728^{\star}\right)\right)$ & 0,97 \\
\hline $\mathrm{L}_{3}=353,89$ & $Y=214,6914^{*}+2875,7325^{\star} /\left(1+\exp \left(-\left(x-66,666^{\star}\right) / 7,544^{*}\right)\right)$ & 0,98 \\
\hline $\mathrm{L}_{4}=521,86$ & $Y=191,3454^{\star}+3021,5025^{\star} /\left(1+\exp \left(-\left(x-60,5377^{\star}\right) / 8,014^{\star}\right)\right)$ & 0,98 \\
\hline $\mathrm{L}_{5}=741,64$ & $Y=187,003^{\star}+3566,7509^{\star} /\left(1+\exp \left(-\left(x-58,5197^{\star}\right) / 9,0967^{\star}\right)\right)$ & 0,98 \\
\hline \multicolumn{3}{|l|}{ Fitomassa fresca total } \\
\hline $\mathrm{L}_{1}=125,30 \mathrm{~mm}$ & $Y=4 X 61,48^{*} \operatorname{EXP}(-(x-96,87) / 24,49) /\left(1+\operatorname{EXP}\left(-\left(x-96,87^{*}\right) / 124,49^{*}\right)\right)^{2}$ & 0,95 \\
\hline $\mathrm{L}_{2}=298,35$ & $Y=4 X 172,11^{*} \operatorname{EXP}(-(X-97,39) / 13,72) /\left(1+\operatorname{EXP}\left(-\left(X-97,39^{\star}\right) / 13,72^{*}\right)\right)^{2}$ & 0,95 \\
\hline $\mathrm{L}_{3}=353,89$ & $Y=4 X 336,34^{*} \operatorname{EXP}(-(x-95,23) / 11,10) /\left(1+\operatorname{EXP}\left(-\left(x-95,23^{*}\right) / 11,10^{*}\right)\right)^{2}$ & 0,96 \\
\hline $\mathrm{L}_{4}=521,86$ & $Y=4 X 337,78^{*} \operatorname{EXP}(-(x-95,61) / 10,91) /\left(1+\operatorname{EXP}\left(-\left(x-95,61^{*}\right) / 10,91^{*}\right)\right)^{2}$ & 0,89 \\
\hline $\mathrm{L}_{5}=741,64$ & $Y=4 X 361,13^{*} \operatorname{EXP}(-(X-94,22) / 11,56) /\left(1+\operatorname{EXP}\left(-\left(x-94,22^{*}\right) / 11,56^{*}\right)\right)^{2}$ & 0,92 \\
\hline \multicolumn{3}{|l|}{ Fitomassa seca total } \\
\hline $\mathrm{L}_{1}=125,30 \mathrm{~mm}$ & $Y=1 /-0,0193^{*}+0,0000000263^{*} x^{3}+298,3469^{*} / x^{2}$ & 0,99 \\
\hline $\mathrm{L}_{2}=298,35$ & $Y=1 /-0,0529^{\star}+0,00000002947^{\star} x^{3}+387,558^{*} / x^{2}$ & 0,99 \\
\hline $\mathrm{L}_{3}=353,89$ & $Y=4 X 125,48^{*} \operatorname{EXP}(-(x-96,62) / 11,43) /\left(1+\operatorname{EXP}\left(-\left(x-96,62^{\star}\right) / 11,43^{*}\right)\right)^{2}$ & 0,99 \\
\hline $\mathrm{L}_{4}=521,86$ & $Y=4 X 132,67^{\star} \operatorname{EXP}(-(x-97,29) / 10,75) /\left(1+\operatorname{EXP}\left(-\left(x-97,29^{*}\right) / 10,75^{*}\right)\right)^{2}$ & 0,96 \\
\hline $\mathrm{L}_{5}=741,64$ & $\mathrm{Y}=4 \mathrm{X} 142,95^{*} \operatorname{EXP}(-(\mathrm{X}-96,16) / 11,34) /\left(1+\operatorname{EXP}\left(-\left(\mathrm{X}-96,16^{*}\right) / 11,34^{*}\right)\right)^{2}$ & 0,98 \\
\hline
\end{tabular}

* Significativo a 0,05 de probabilidade 
A.

$$
\text { B. }
$$

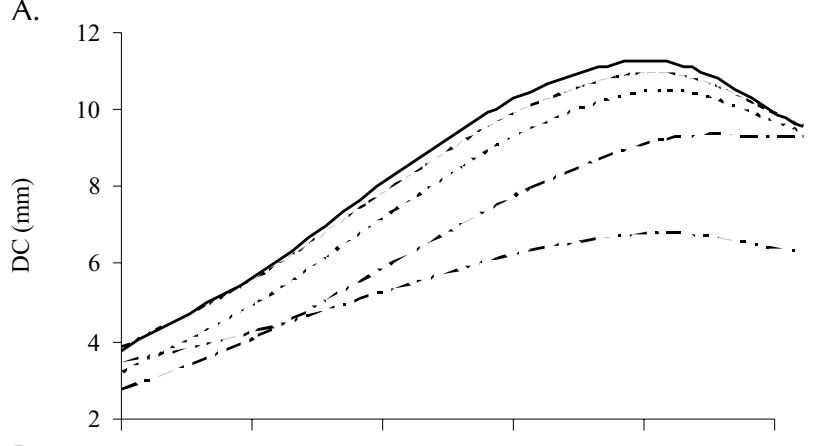

B.

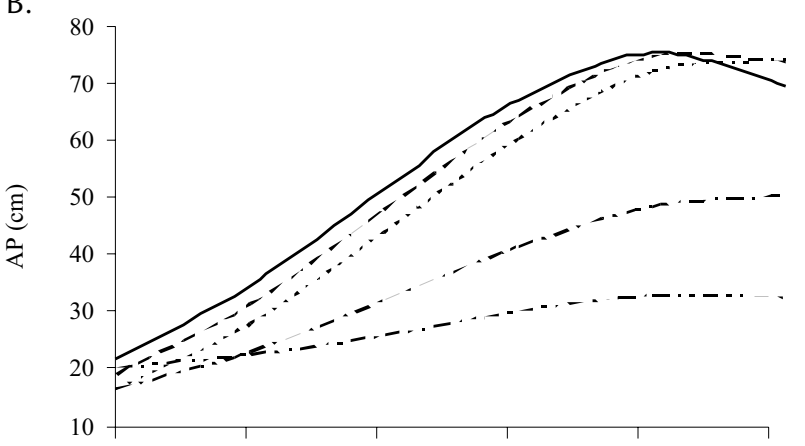

C.

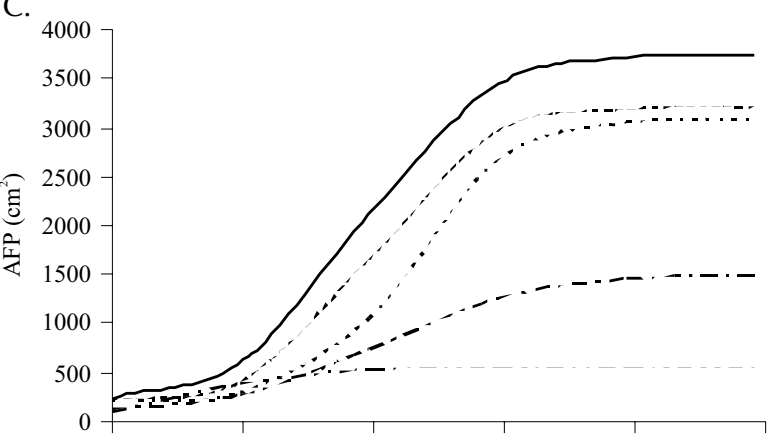

D.

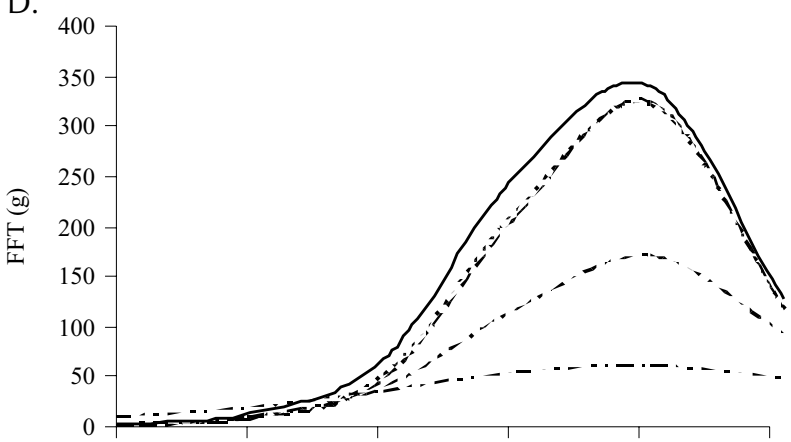

E.

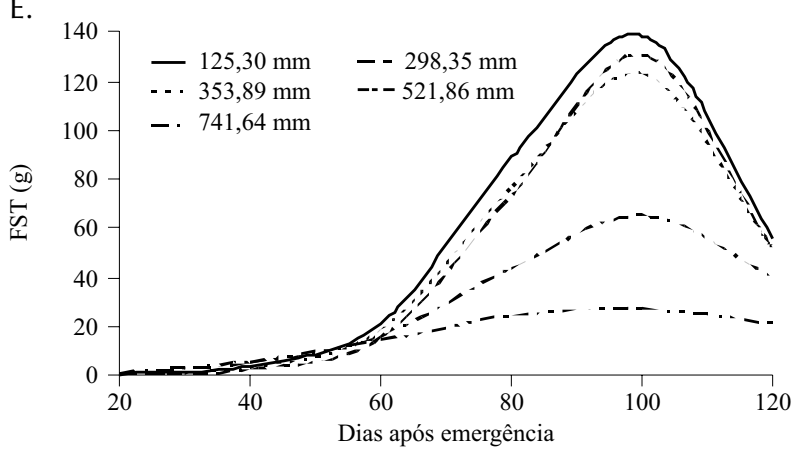

Figura 2. Efeitos das lâminas de irrigação sobre variáveis de crescimento (DC - diâmetro caulinar; AP - altura da planta; AFP - área foliar por planta; FFT - fitomassa fresca total; FST - fitomassa seca total) ao longo do ciclo (DAE) da cv. BRS 200 Marrom e E). A menor lâmina utilizada no experimento reduziu, drasticamente, o acúmulo de matéria fresca e seca devido, principalmente, à forte redução da área foliar; já nas plantas irrigadas com a maior lâmina, aumentou a acumulação de biomassa. É interessante se observar a redução da fitomassa, próximo aos $100 \mathrm{DAE}$, da mesma forma como ocorreu ao serem analisados os dados relativos ao regulador de crescimento; este período coincide com o início de colheita de capulhos em que, na fase de frutificação, os assimilados se destinaram, essencialmente, para os frutos em formação, os principais drenos da planta (Souza \& Beltrão, 1999).

\section{Variáveis de Rendimento}

Os resultados da análise de variância e de regressão para abertura do primeiro capulho e para rendimento estão na Tabela 5, verificando-se que ambas as variáveis foram favorecidas pelas lâminas de irrigação $(\mathrm{p}<0,01)$, sem efeito da aplicação do regulador de crescimento; na interação (D x L) não houve diferença significativa, indicando que o efeito da irrigação não dependeu da aplicação do cloreto de mepiquat.

Em relação à abertura do primeiro capulho, observou-se aumento no número de dias, em função das quantidades de água aplicadas ( $p<0,01)$; enquanto em $L_{1}$ foram necessários 96,25 dias para as plantas abrirem o capulho, com as lâminas $L_{3}, L_{4}$ e $L_{5}$ este valor foi muito aproximado, em torno de 105 dias (Figura 3); a antecipação no tratamento de menor irrigação pode ser decorrente de um provável déficit hídrico resultando em uma reação fisiológica da planta, para garantir a perpetuação da espécie (Souza \& Beltrão, 1999). Com relação ao rendimento, sempre que se reduziu o volume de água fornecido ao algodoeiro BRS 200 Marrom, diminuiu a produtividade (Figura 4); com base na respectiva equação, ocorreram acréscimos, em relação a $L_{1}$, de 160,03, 200,70, 292,11 e 339,98\% em $L_{2}, L_{3}, L_{4}$ e $L_{5}$, respectivamente, denotando-se um rendimento máximo e mínimo para o algodoeiro BRS 200 Marrom, de 3311,92 $\mathrm{kg} \mathrm{ha}^{-1}$ para $\mathrm{L}_{5}$

Tabela 5. Resumo da análise de variância para abertura do primeiro capulho (APC) e rendimento (R) do algodoeiro colorido BRS 200, obtidos com diferentes doses do regulador de crescimento e quantidades de água de irrigação

\begin{tabular}{|c|c|c|}
\hline \multirow{2}{*}{ Fonte de variação } & \multicolumn{2}{|c|}{ Quadrados médios } \\
\hline & APC & $\mathbf{R}^{1}$ \\
\hline Dose de Regulador (D) & $5,07^{\mathrm{ns}}$ & $39,77^{\mathrm{ns}}$ \\
\hline Lâmina (L) & $277,75^{\star *}$ & $1088,59 * *$ \\
\hline Reg. Pol. Linear & $277,75^{\star *}$ & 935,11 ** \\
\hline Reg. Pol. Quadr. & $1,39 \mathrm{~ns}$ & $172,18^{*}$ \\
\hline Reg. Pol. Cúbica & $8,03^{\text {ns }}$ & $27,85^{\text {ns }}$ \\
\hline$D \times L$ & $2,01^{\mathrm{ns}}$ & $73,67^{\mathrm{ns}}$ \\
\hline Bloco & 15,41 ** & $194,07 *$ \\
\hline Resíduo & 3,18 & 66,24 \\
\hline \multirow[t]{2}{*}{ CV (\%) } & 1,74 & 25,17 \\
\hline & \multicolumn{2}{|c|}{ Médias } \\
\hline Dose de regulador & dias & $\mathrm{kg} \mathrm{ha}^{-1}$ \\
\hline $\mathrm{D}_{1}=0 \mathrm{~g}$ i.a ha ${ }^{-1}$ & 101,80 & 2241,92 \\
\hline$D_{2}=50 \mathrm{~g}$ i.a ha-1 & 101,75 & 2219,22 \\
\hline$D_{3}=75 \mathrm{~g}$ i.a ha-1 & 102,40 & 2136,32 \\
\hline $\mathrm{D}_{4}=100 \mathrm{~g}$ i.a ha-1 & 102,8 & 2090,96 \\
\hline
\end{tabular}


(741,64 mm) e 760,72 $\mathrm{kg} \mathrm{ha}^{-1}$ para $\mathrm{L}_{1}(125,30 \mathrm{~mm})$, respectivamente.

Não houve influência do cloreto de mepiquat (Tabela 5) sobre a produtividade do algodoeiro BRS 200. Beltrão et al. (2001a), estudando três níveis do regulador cloreto de mepiquat (25, 50 e 75 g i.a ha-1), em diferentes fases do ciclo constataram, também, não haver influência sobre o rendimento do algodoeiro irrigado nem sobre a qualidade da fibra. Os benefícios da aplicação de reguladores de crescimento em cultivos de algodão se devem, principalmente, à redução do crescimento vegetativo e maior equilíbrio entre partes vegetativa e reprodutiva, conforme referido por Meredith Júnior \& Wels (1989) e por Athayde \& Lamas (1999), facilitando o manejo da cultura.

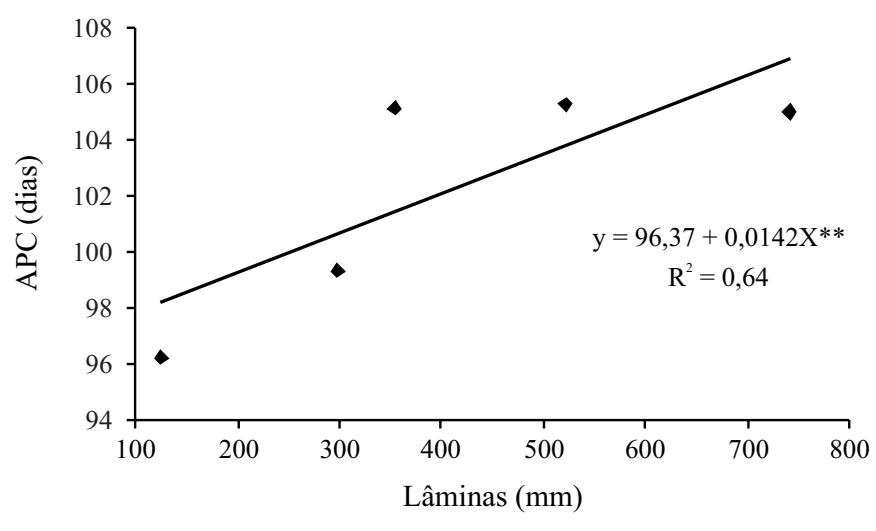

Figura 3. Dias para abertura de capulho do algodoeiro BRS 200 Marrom, em função das diferentes quantidades de água de irrigação

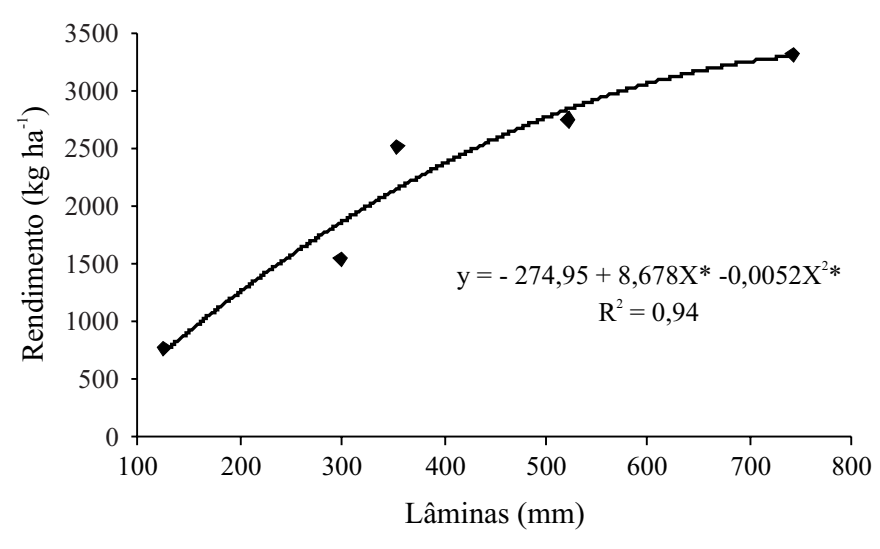

Figura 4. Rendimento do algodoeiro BRS 200 Marrom, em função das diferentes quantidades de água de irrigação

\section{CONCLUSÕES}

1. Lâminas pequenas de irrigação alteram a morfologia da planta, em virtude de reduzir a sua altura, o diâmetro do caule, a área foliar e a fitomassa.

2. Menores altura de planta e área foliar do algodoeiro foram observadas com a dose de $50 \mathrm{~g}$ i.a ha ${ }^{-1}$ de cloreto de mepiquat; menos fitomassa foi formada na dose de 100 g i.a. ha-1 do regulador.
3. A irrigação com lâmina de $741,64 \mathrm{~mm}$ resultou em maior produção de algodão em caroço, da ordem de 339\%, em comparação com a de 125,30 mm.

4. Não se constatou efeito das doses do cloreto de mepiquat sobre variáveis de produção; também não se notou relação entre lâminas de irrigação e doses do regulador sobre crescimento e produção de algodão.

\section{LITERATURA CITADA}

Almeida, O. A. de; Beltrão, N. E. de M.; Guerra, H. O. C. Efeito do encharcamento do solo no crescimento, desenvolvimento e produção do algodoeiro herbáceo. In: Reunião Nacional do Algodão, 6, 1990. Fortaleza. Resumos... Campina Grande: MARA/EMBRAPA-CNPA, 1990. p.187.

Almeida, R. P.; Silva, C. A. D. Manejo integrado de pragas do algodoeiro. In: Beltrão, N.E.M. (ed.). O agronegócio do algodão no Brasil. Brasília: Embrapa/Algodão, 1999. p.753-820.

Atahyde, M. L. F.; Lamas, F. M. Aplicação de cloreto de mepiquat no algodoeiro. Pesquisa Agropecuária Brasileira, Brasília, v.34, n.3, p.369-375, 1999.

Barros, M. A. L.; Santos, R. F. dos. Aspectos econômicos e sociais da produção de algodão arbóreo no Nordeste do Brasil. In: Congresso Brasileiro de Algodão, 1, 1997. Fortaleza... Anais. Campina Grande: EMBRAPA/CNPA, 1997. P.82-84.

Beltrão, N. E. de M. O agronegócio do algodão no Brasil. Brasília: Empresa de Comunicação para Transferência de Tecnologia, 1999. 78p.

Beltrão, N. E. de M.; Almeida, O. A. de; Pereira, J. R.; Fideles Filho, J. Metodologia para estimativa do crescimento do fruto e do volume absoluto e relativo da planta do algodoeiro. Revista de Oleaginosas e Fibrosas, Campina Grande, v.5, n.1, p.283-289, 2001a.

Beltrão, N. E. de M.; Vasconcelos, O. L.; Fideles Filho, J. F.; Ribeiro, V. G.; Pereira, J. R. Análise do crescimento do algodoeiro herbáceo em sistema de produção de elevada tecnologia, irrigada via pivô central. In: Congresso Brasileiro de Algodão, 3, 2001. Campo Grande. Anais... Campina Grande: EMBRAPA Algodão, 2001b. p.435-438.

Chen, D.; Chen, Y.; Yang, C. Q.; He, Z. P. The effects on the boll weight ant the source-sink characteristics in the coordination of nitrogen fertilizer in cotton. Cotton Science, Brisbane, v.14, n.5, p.147-150, 2002.

CONAB - Companhia Nacional de Abastecimento - Indicadores da agropecuária. Brasília: Ministério da Agricultura e do Abastecimento. http://www.conab.gov. 20 Nov. 2003.

CONAB - Companhia Nacional de Abastecimento - Indicadores da agropecuária. Brasília: Ministério da Agricultura e do Abastecimento. http://www.conab.gov. 30 Mai. 2005.

EMBRAPA - Empresa Brasileira de Pesquisa Agropecuária. O algodão colorido no Brasil. Campina Grande: Embrapa Algodão 2000. 14p.

EMBRAPA - Empresa Brasileira de Pesquisa Agropecuária. Histórico da Embrapa-Algodão, 2001. http://www.embrapa.org.br. 02/nov/2003.

Ferreira, P. V. Estatística experimental aplicada à agronomia. 2.ed. Revisada e ampliada. Maceió: UFAL/EDUFAL/FUNDEPES, 2000. 437p.

R. Bras. Eng. Agríc. Ambiental, v.11, n.3, p.284-292, 2007. 
Freire, E. C.; Andrade, F. P. de; Santana, J. C. F. de; Pedrosa, M. B. Melhoramento do algodoeiro de fibras longas para cultivo sob condições irrigadas no Nordeste do Brasil. In: Congresso Brasileiro de Algodão, 2, 1999. Ribeirão Preto. Anais... Campina Grande: Embrapa Algodão, 1999. p.566-568.

Grimes, D. W.; Carter, L. M. A linear rule for direct nondestructive leaf area measurements. Agronomy Journal, Madison, v.3, n.61, p.477-479, 1969.

Guthrie, D.; Landivar, J.; Munier, D.; Stichler, C.; Weir, B. Pix application strategies. Cotton Physiology Today, Memphis, v.6, n.4, p.4-5, 1995.

ICAC Recorder. International Cotton Advisory Committee, Washington, v.10, n.4, p.36, 1992.

Lamas, F. M. Regulador de crescimento na cultura do algodoeiro: comparação entre produtos e formas de fracionamento de doses. In: Congresso Brasileiro de Algodão, 3. 2001. Campo Grande. Anais... Campina Grande: Embrapa Algodão, 2001. p.514-518.

Meredith Jr., W. R.; Well, R. Potential for increasing cotton yields through enchanced partitioning to reproductive strutures. Crop Science, Madison, v.29, n.3, p.636-639, 1989.

Raven, P. H.; Evert, R. F.; Eichhorn, S. E. Biologia Vegetal. 6.ed. Rio de Janeiro: 2001. 905p.

Reddy, K. R.; Boone, M. L.; Reddy, A. R.; Hodges, H. F.; Turner, S. B.; McKinion, J. M. Developing and validating a model for plant growth regulator. Agronomy Journal, Madison, v.87, n.6, p.1100-1105, 1995.
Reichardt, K. Processos de transferência no sistema solo-plantaatmosfera. Fundação Cargill. 1985. 445p.

Silva, B. B.; Souza, C. B.; Rao, T. V. R.; Azevedo, P. V.; Espínola Sobrinho, J. Efeitos do déficit hídrico sobre a fenometria e a tecnologia de fibra do algodoeiro herbáceo. Revista Brasileira de Engenharia Agrícola e Ambiental, Campina Grande, v.2, n.1, p.42-46, 1998.

Souza, C. C. Avaliação de métodos de determinação de água disponível em diferentes solos na cultura do algodoeiro herbáceo. Areia: UFPB, 1999. 84p. Dissertação Mestrado.

Souza, C. C.; Oliveira, F. de. A.; Silva, I. de. F. da.; Andrade, A. de. P: Manejo de irrigação e adubação nitrogenada na cultura do algodoeiro herbáceo. Revista Brasileira de Engenharia Agrícola e Ambiental, Campina Grande, v.3, n.2, p.125130, 1999.

Souza, J. G. de; Beltrão, N. E. de M. Fisiologia. In: Beltrão, N. E. de M. (org.). O agronegócio do algodão no Brasil. Brasília: Embrapa-Comunicação para Transferência de Tecnologia, 1999. v.1, cap.IV, p.89-116.

SUDENE - Superintendência do Desenvolvimento de Nordeste. Isótopos ambientais aplicados a um estudo hidrológico do Nordeste brasileiro. Recife: SUDENE/MINTER, 1979. 58p.

Taiz, L.; Zeiger, E. Fisiologia Vegetal. 3.ed. Porto Alegre: Artmed, 2004, 613p.

Thornthwaite, C. W.; Mather, J. R. The water balance. New Jersey: Drexel Institute of Technology, 1955. 104p. Publications in Climatology 